\title{
Interactive Balance and Walking Training for Stroke Survivors
}

\author{
C. Magnusson ${ }^{1}$, S. A. Ólafsdóttir², H. Caltenco' ${ }^{1}$, K. Rassmus-Gröhn ${ }^{1}$, T. Hafsteinsdottir ${ }^{3}$, H. Jónsdóttir ${ }^{2}$, \\ I. Hjaltadóttir ${ }^{2}$, B. Rydeman ${ }^{1}$ \\ ${ }^{1}$ Department of Design Sciences, Lund University, P.O. Box 221 00, Lund, Sweden \\ \{charlotte, hector.caltenco, kirre, bitte.rydeman\}@certec.lth.se \\ ${ }^{2}$ Faculty of Nursing, University of Iceland, Eirbergi, Eiríksgötu 34, 107 Reykjavík, Iceland \\ \{sao9, helgaj, ingihj\}@hi.is \\ ${ }^{3}$ Department of Rehabilitation, Nursing, University Medical Center Utrecht, Heidelberglaan 100, 3584 CX Utrecht, \\ Netherlands \\ t.hafsteinsdottir@umcutrecht.nl
}

\begin{abstract}
In the ActivAbles and STARR projects we have developed interactive training tools for stroke survivors. A prototype system includes an interactive balance foam pad, feedback lamps and a step counting game app which all connect to a central server. The feedback is designed to be inclusive - designs are multimodal, and the setup is flexible and can easily be adapted. We describe the system and report results from a feasibility study with 10 stroke survivors who used the system for a longer period in the home.
\end{abstract}

\section{KEYWORDS}

Stroke, balance training, interactive, rehabilitation, inclusive, multimodal ${ }^{1}$.

\section{INTRODUCTION}

Stroke is the leading cause of long-term disability in western countries [1] resulting in life-altering changes for both the stoke survivor and their closest family. Loss of balance is common among stroke-survivors [2]. Difficulties with posture and balance make it difficult for persons to walk, and thus to leave the home to socialize or perform other outdoor tasks. After intensive rehabilitation in a dedicated rehabilitation setting, the majority of stroke survivors with residual impairments are discharged and then rely on informal caregivers (frequently close family members) [3]. Effective rehabilitation of stroke survivors is required to help them accomplish daily activities (cooking, washing, etc.) and lead an

*Produces the permission block, and copyright information

†The full version of the author's guide is available as acmart.pdf document

${ }^{1}$ It is a datatype.

Permission to make digital or hard copies of part or all of this work for personal or classroom use is granted without fee provided that copies are not made or distributed for profit or commercial advantage and that copies bear this notice and the full citation independent life. After discharge, most of this rehabilitation occurs at home, through performing different types of exercises and activities, such as training in activities of daily living, strength training, cardio-vascular training, balance training, gait training and postural control [4].

Exercises, however, can be repetitive and difficult to perform correctly, and may also be considered boring. This leads to stroke survivors losing confidence and giving up on rehabilitation, and losing the benefits it could provide. Thus, it is important to investigate how to better support the continuation of rehabilitation at home. Donker et. al. [5] used interactive tiles for balance training during stroke rehabilitation sessions. They showed that providing real time visual feedback improved motivation and was helpful for balance rehabilitation. Auditory feedback via sonification is also helpful for improving motoric skills [6]. Stienstra et. al. [7] studied how movement sonification improves proprioception during speedskating. Other relevant work has proven the benefits of movement sonification on proprioception and awareness [8,9]. Moreover, music and rhythm therapy are proven to help stroke survivors increase the feeling of being connected to their own body. A study by Thornberg et. al. [10] shows that music and rhythm exercises were considered positively challenging for stroke survivors, while facilitating motor planning and coordination. Music is also a significant motivation factor while training which can give emotional pleasure [10]. Pleasant sounds tend to persuade the user into behavioural change [7].

on the first page. Copyrights for third-party components of this work must be honored. For all other uses, contact the owner/author(s).

WOODSTOCK'97, July 2016, El Paso, Texas USA

(C) 2016 Copyright held by the owner/author(s). 123-4567-24-567/08/06 . . \$15.00 DOI: $10.1145 / 123 \_4$ 
The present paper presents a system of interactive prototypes designed to support the continuation of balance rehabilitation at home, and report on results from a feasibility study. The user studies leading up to the current designs are described in [11] and [12].

\section{INTERACTIVE PROTOTYPES}

In this section we describe the final version of our prototypes. Earlier designs, as well as the early design process is described in [13] (balance pad) and [14] (step counting game).

Foam pad, ActiveFOAM. ActivFOAM is based on a standard foam pad used for balance rehabilitation, which was made pressure sensitive by the addition of conductive and resistive materials. The pad was covered with a sandwich design of pressure-sensing fabric material (FlexTiles [15], Figure 1). ActivFOAM connects to an android tablet USB port, and it is the android tablet that shows the visual feedback and connects via WiFi to a local OpenHab server running on a Raspberry Pi (Figure 2, left). Sounds are currently not played by the tablet, but by the server. ActivFOAM comes with a selection of interactive activities; you can play music from a music player, you can play a couple of PureData music pieces and soundscapes interactively, you can play games (an audio game, pong and a game where you avoid obstacles on a course) and you can also use only the visual pressure feedback to see the pressure distribution and center of balance.

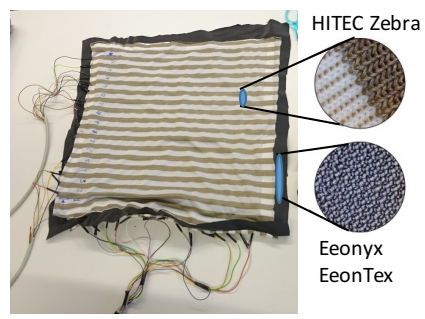

Figure 1: Pressure sensor matrix cover for ActivFOAM.

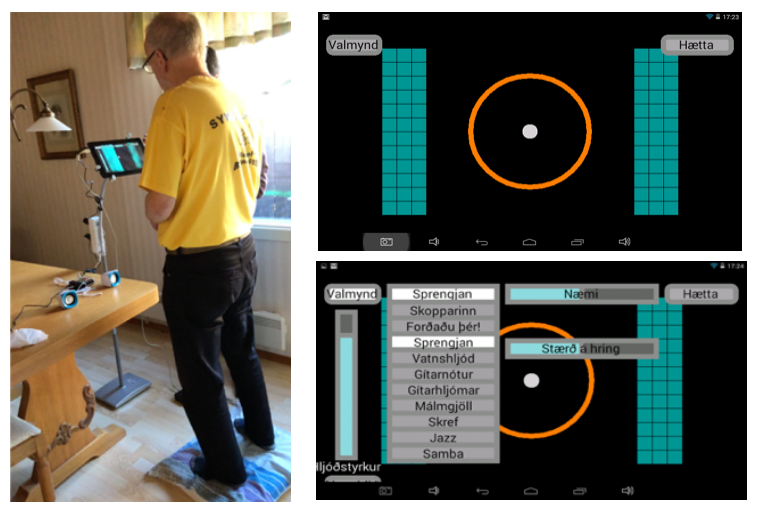

Figure 2: The final ActiveFOAM setup.

Both the pressure sensitivity, and how sensitive the interactive foam pad is to changes in balance can be adjusted. The volume of the sounds is controlled via a slider on the screen (figure 2, right). ActiveFoam is connected to feedback lamps that can display the progress (see below) via the local server. This server can be used to set a daily goal for balance training, e.g. 10 or 20 minutes per day. Training can be divided into several sessions per day. To count a use session, ActivFOAM registers when someone steps on and off the balance pad.

Feedback lights. For progress monitoring, we developed several different prototype progress lamps (figure 3).
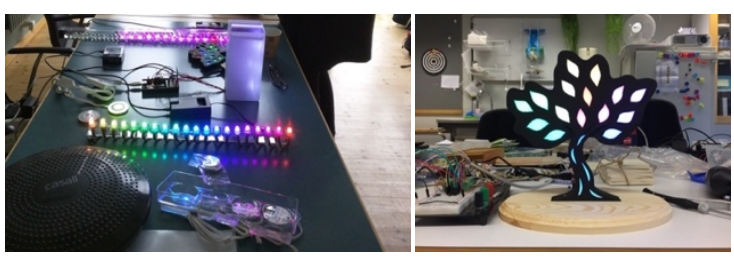

Figure 3: Different versions of the feedback lamps.

Depending on the use case, you may want to monitor progress on one or several activities, and lamps with a single row of LEDlamps, as well as a lamp with branches for three activities were developed. The tree-shaped lamp (figure 3, right) can monitor a single activity (the whole tree fills up gradually), or up to three different activities where each branch reflects a different activity.

Step counting game. The design of this game is built on short mini games which appear in a semi-random fashion during a walk. The game has settings that allow customization - games can increase in difficulty, or stay the same, and it is also possible to completely remove the games leaving only the step progress screen (Figure 4, left). The app has two different graphical themes, stars (figure 4, middle) or dog (figure 4, right).
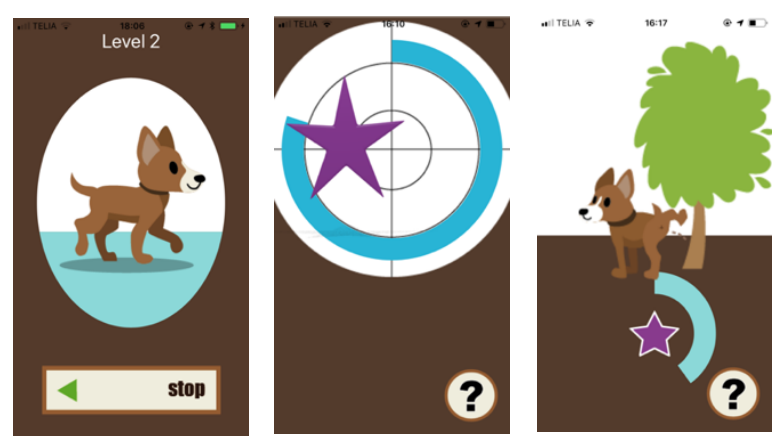

Figure 4: Three screens from the game.

The mini games are physical in nature, you are challenged to walk a little faster, to turn around and point the phone to a specified direction to catch a star or help the dog pee (Figure 4, middle and right), to tilt or shake the phone etc. The game can connect to the feedback lamps through the local server. The user can specify both game goals (how long should a walk be), and day goals (how much you walk during a whole day). These goals can be specified either as steps, distance or active time. The game connects to the server vis Bluetooth LE and the progress towards the goals is also shown on the lamps. 


\section{FEASIBILITY STUDY}

The feasibility study of ActivABLES (balance pad, lamps, activity game app) was conducted in Iceland in the spring of 2018 using mixed methods. We had 10 stroke survivors with slight to moderate disability after stroke (Modified Rankin Scale 2-3) using ActivABLES for four weeks in their own home with support from their caregivers. All the stroke survivors tested ActivFOAM with the balance exercises and four used the Walking STARR application. Before the test, participants were given pedometers, to get a baseline of how physically active they were. Before and after the 4-week use, we performed some quantitative functional measures, including Berg Balance Scale (BBS) on balance [16]. Wilcoxon signed rank test was used to analyze changes between pre- and post-measures with the significance level of $\mathrm{p}<0.05$ After the 4-week use we took individual qualitative interviews with each stroke survivor and each caregiver. Feasibility had the predetermined codes of acceptability, demand, implementation and practicality [17] and subcategories were analysed for each code.

\section{RESULTS AND DISCUSSION}

\subsection{Feasibility study results}

In general, the participants were impressed with ActivFOAM and reported interest in further use for themselves as well as for future stroke survivors. The stroke survivors did significantly better on the balance measures after the 4-week use (see Table 1) and both stroke survivors and their caregivers reported noticed functional improvements, especially on the balance. They also said they were more stable while walking and relied less on their assistive devices. Both stroke survivors and caregivers described the importance of instant feedback while doing exercises and majority of participants thought the feedback in forms of light were encouraging. The stroke survivors reported the excitement of collecting scores while exercising. At the same time, they express the need for more variety of exercises/games. About half of the stroke survivors did use the possibilities for progression of the exercises (by making the paddle and the circle smaller) and they thought that was a good option. The stroke survivors were mostly independent in using ActivFOAM and did not get a lot of support from their caregivers.

The four stroke survivors that tested the step counting game, were most delighted with the step counts and thought it was encouraging to see the steps taken and what to aim for. They had problems with the games and were not very interested in trying them out. One stroke survivor said the activities with the dog were too childish. Depending on the participant, the app has been used for short walks indoors (4-8 $\mathrm{min}$ ) or longer, outdoor, activity.

\subsection{Discussion}

It is encouraging to see that already such a short home intervention as four weeks can generate significant results. It has been shown that four weeks of supervised balance training for 20 minutes a day at a rehab center will generate significant results also in the chronic phase of stroke [18]. In our case is that the training was unsupervised, on a comparatively low cost device and done in the home - thus having to be integrated in the daily activities of the participants. The pedometer use before the intervention generally indicated quite a low activity level, something which shows the importance of developing these kinds of designs and interventions.

Table 1. Participants and balance measures

\begin{tabular}{llllll}
\hline gender & age & $\begin{array}{l}\text { time since } \\
\text { stroke }\end{array}$ & $\begin{array}{l}\text { side of } \\
\text { hemiparesis }\end{array}$ & $\begin{array}{l}\text { pre- } \\
\text { BBS }\end{array}$ & $\begin{array}{l}\text { post- } \\
\text { BBS }\end{array}$ \\
\hline $\mathrm{f}$ & 63 & 23 years & left & 42 & 43 \\
$\mathrm{f}$ & 55 & 9 months & right & 49 & 54 \\
$\mathrm{~m}$ & 71 & 15 months & left & 33 & 39 \\
$\mathrm{~m}$ & 79 & 5 months & right & 48 & 49 \\
$\mathrm{~m}$ & 66 & 26 months & right & 31 & $\mathrm{X}^{*}$ \\
$\mathrm{~m}$ & 74 & 19 months & left & 45 & 46 \\
$\mathrm{~m}$ & 67 & 8 months & left & 48 & 48 \\
$\mathrm{f}$ & 73 & 30 years & left & 38 & 42 \\
$\mathrm{f}$ & 78 & 4 years, & left & 43 & 44 \\
$\mathrm{f}$ & 72 & $\begin{array}{l}3 \text { months } \\
\text { 14 months }\end{array}$ & right & 44 & 48 \\
\hline
\end{tabular}

*was not able to take part in the post-testing

\begin{tabular}{|c|c|c|c|}
\hline & pre-test* & post-test* & p \\
\hline $\begin{array}{l}\text { BBS } \quad(0- \\
56)\end{array}$ & $\begin{array}{l}43.5 \\
47.3)\end{array}$ & $\begin{array}{l}46.0 \quad(43.0- \\
48.0)\end{array}$ & 0.013 \\
\hline
\end{tabular}

*median $\left(1^{\text {st }}\right.$ and $3^{\text {rd }}$ quartile $)$

Compared to the Wii balance board, our balance pad is soft, potentially safer since you are not standing on a raised hard platform and can also show the pressure distribution over the surface. The REHAP balance tiles [5], which are designed for supervised training allow the creation of different step exercises, respond to pressure at specific points. Our setup is designed for unsupervised training, and the games and other feedback are also designed for our user group; for stroke survivors it is important to limit the amount of information the user has to process. Additionally, our pad is part of a system - through the server it is possible to link additional devices, apps and potentially also embedded sensors to feedback lamps or other feedback devices as well as to games. Although the variety provided by our proof of concept games and activities was appreciated, more elaborate software feedback will be needed in the long run eg. time spent training, high score in games, qualitative feedback on balance as well as level support.

The lamps have been generally well appreciated and seeing the lights change has been felt to be encouraging. Still, the lamps as they are now, are a proof of concept and future developments should involve artists/designers to create designs that are both 
aesthetically pleasing and useful. A potential advantage of the step counting game connecting to the lamps, is that you can see your progress without constantly having to monitor your phone.

A major challenge in turned out to be the charging of devices. Our current solution is to keep the system connected to a power outlet, but since we use existing standard technology when possible (eg tablets) designed for charging, this isn't an ideal solution. Although products aimed at facilitating charging are beginning to reach the market, charging is still a challenge that needs to be considered in any system intended for use in the home by our user group.

While the ActiveFOAM setup has been generally successful, it is clear from the test results that the step counting game requires redesign. Since we have had earlier users who thought the minigames were fun (especially our first beta tester used the app extensively), we have decided to keep the mini games as one possibility, but add two completely new games: one game where you automatically pick up keys and chests with treasure which can later be unlocked; and one version which is less of a game - each completed exercise moves you forward in a journey through a landscape. This new version of the app will be tested during 2019.

To support users with different perceptual abilities, we have included activities using both sounds, visual feedback and haptic feedback (vibrations) in our designs. This comes with two issues: 1) too much simultaneous information may overwhelm the user. It is common for stroke survivors to have brain fatigue, which makes multimodality a potential problem. 2) to avoid overwhelming the user, one could use settings. But settings in themselves run the risk of overwhelming the user. So far, we have opted for multimodality as our basic approach, but added a limited number of settings.

\section{CONCLUSIONS}

Our test results confirm our designs with regards to the interactive balance pad and the feedback lamps. The participants in the four week feasibility test significantly improve their balance, and also generally appreciate the pad and the lamps. What remains to be developed is the interaction and feedback - more games and activities, better game mechanics and improved overview of long term results. We have confirmed that ActivFOAM has a design that is stable and quite robust. The foam pad itself is also quite flexible. One can stand on it, but it is also possible to sit on it. The direct activity feedback provided by the lamps has been appreciated, but also the lamps need further development with regards to both functionality and aesthetics. For the step counting game, the picture is less clear. Although some elements of the design got positive feedback for some of our users, clearly further development and testing is needed.

\section{ACKNOWLEDGMENTS}

The reported work has been funded by NordForsk (project ActivAbles) and EU Horizon 2020 (project STARR, grant agreement 689947). The authors also gratefully acknowledge the help from all test participants, and in particular we want to thank Strokeföreningen Malmö, Sweden and Heilahell, Iceland.

\section{REFERENCES}

[1] C.D. Wolfe, The impact of stroke, Br. Med. Bull. 56 (2000) 275-286. doi:10.1258/0007142001903120.

[2] Stroke.org.uk, Balance problems after stroke, (n.d.) https://www.stroke.org.uk/resources/balance-problems-after-stroke (accessed May 24, 2018).

[3] B.J. Lutz, M.E. Young, K.J. Cox, C. Martz, and K.R. Creasy, The crisis of stroke: experiences of patients and their family caregivers, Top. Stroke Rehabil. 18 (2011) 786-797. doi:10.1310/tsr1806-786; 10.1310/tsr1806786.

[4] H.K. Kristensen, C. Ytterberg, D.L. Jones, and H. Lund, Research-based evidence in stroke rehabilitation: an investigation of its implementation by physiotherapists and occupational therapists, Disabil. Rehabil. 38 (2016) 2564-2574. doi:10.3109/09638288.2016.1138550.

[5] V. Donker, P. Markopoulos, and B. Bongers, REHAP Balance Tiles: a modular system supporting balance rehabilitation, in: Proc. 9th Int. Conf. Pervasive Comput. Technol. Healthc., 2015. doi:10.4108/icst.pervasivehealth.2015.259278

[6] A.O. Effenberg, Movement Sonification: Motion perception, behavioral effects and functional data, in: Proc. 2nd Int. Work. Interact. Sonification, 2007.

[7] J. Stienstra, K.C.J. Overbeeke, and S. Wensveen, Embodying Complexity Through Movement Sonification: Case Study on Empowering the Speedskater, in: Proc. 9th ACM SIGCHI Ital. Chapter Int. Conf. Comput. Interact. Facing Complex., 2011: pp. 39-44. doi: $10.1145 / 2037296.2037310$.

[8] F. Feltham, and L. Loke, The slow floor: increasing creative agency while walking on an interactive surface, Proc. 8th Int. Conf. Tangible, Embed. Embodied Interact. (2014) 105-112. doi:10.1145/2540930.2540934.

[9] P. Srinivasan, D. Birchfield, G. Qian, and A. Kidané, A pressure sensing floor for interactive media applications, ACE' 05 Proc. 2005 ACM SIGCHI Int. Conf. Adv. Comput. Entertain. Technol. 265 (2005) 278-281. doi:http://doi.acm.org/10.1145/1178477.1178526.

[10] K. Thornberg, S. Josephsson, and I. Lindquist, Experiences of participation in rhythm and movement therapy after stroke, Disabil. Rehabil. 36 (2014) 1869-1874 doi:10.3109/09638288.2013.876107.

[11] C. Magnusson, H.A. Caltenco, D. McGookin, M. Kytö, I. Hjaltadóttir, T.B. Hafsteinsdóttir, H. Jónsdóttir, and I. Bjartmarz, Tangible interaction for stroke survivors: Design recommendations, in: TEI 2017 - Proc. 11th Int. Conf. Tangible, Embed. Embodied Interact., 2017. doi: $10.1145 / 3024969.3025073$.

[12] C. Magnusson, M. Anastassova, S. Paneels, K. Rassmus-Gröhn, B. Rydeman, G. Randall, L.O. Fernandez, S. Bouilland, J. Pager, and P.-O. Hedvall, Stroke and Universal Design, in: C. Gerald, D. Cormac, M. Larry, and D. Rice (Eds.), Transform. Our World Through Des. Divers. Educ., IOS Press, Dublin, 2018: pp. 854-861. doi:10.3233/978-1-61499-923-2854.

[13] H.A. Caltenco, A. Olsson, A. Aliyari, C. Magnusson, D. McGookin, M. Kytö, I. Hjaltadóttir, T.B. Hafsteinsdóttir, H. Jónsdóttir, and I. Bjartmarz, Designing interactive systems for balance rehabilitation after stroke, in: TEI 2017 - Proc. 11th Int. Conf. Tangible, Embed. Embodied Interact., 2017. doi:10.1145/3024969.3025084.

[14] C. Magnusson, K. Rassmus-gröhn, B. Rydeman, and H. Caltenco, Walk after stroke: initial development of a step counting game for stroke survivors, in: MobileHCI '18 Proc. 20th Int. Conf. Human-Computer Interact. with Mob. Devices Serv. Adjun., ACM, Barcelona, 2018: pp. 237-244. doi:10.1145/3236112.3236145.

[15] P. Parzer, K. Probst, T. Babic, C. Rendl, A. Vogl, A. Olwal, and M. Haller, FlexTiles: A Flexible, Stretchable, Formable, Pressure-Sensitive, Tactile Input Sensor Patrick, in: Proc. 2016 CHI Conf. Ext. Abstr. Hum. Factors Comput. Syst. (CHI EA '16), 2016. doi:10.1145/2851581.2890253.

[16] K.O. Berg, S.L. Wood-Dauphinee, J.I. Williams, and B. Maki, Measuring balance in the elderly: Validation of an instrument, in: Can. J. Public Heal., 1992. doi:10.1016/j.archger.2009.10.008.

[17] D.J. Bowen, M. Kreuter, B. Spring, L. Cofta-Woerpel, L. Linnan, D. Weiner, S. Bakken, C.P. Kaplan, L. Squiers, C. Fabrizio, and M. Fernandez, How We Design Feasibility Studies, Am. J. Prev. Med. (2009). doi:10.1016/j.amepre.2009.02.002.

[18] A. Srivastava, A.B. Taly, A. Gupta, S. Kumar, and T. Murali, Post-stroke balance training: Role of force platform with visual feedback technique, $J$. Neurol. Sci. (2009). doi:10.1016/j.jns.2009.08.051. 